\title{
CORPORATE SOCIAL RESPONSIBILITY: ANALYSIS OF THEORIES AND MODELS
}

\author{
Pavlo Brin ${ }^{1}$
}

\author{
Mohamad Nassif Nehme \\ ${ }^{1}$ Department of Management and Taxation \\ National Technical University, "Kharkov Polytechnic Institute" \\ Kyrpychova str. 2, Kharkiv, Ukraine, 61002
}

\begin{abstract}
Various definitions, forms, and theories related to Corporate Social Responsibilities (CSR) are presented in this article. Nowadays most corporations follow different methodologies to implement CSR approach. But in most cases corporation follow CSR methodology that reflects only its shareholders' interest neglecting its community interest. Critical analysis and comparison for the main CSR theories are presented also, followed by a conclusion about a comprehensive form of CSR that targets both shareholders and community interest.

Three of the main CSR theories and models have been represented and analyzed in this article: The Carroll Theory, The Triple Bottom Line Theory, and The Stakeholder Theories. Since any business corporation has to adopt one of these theories, this study reveals the strength and challenges of every theory. There is no doubt that every theory has been well analyzed by its founder or scholar, but an advanced understand for every theory will make it possible for a corporation's managers and decision makers to implement long term social and environmental strategies with more accurate achievements.

This article is divided into four main sections, the first section presents Carroll's model for CSR, followed by the second which is about the Triple Bottom Line theory for CSR, and the third represents the Stakeholder theory. The fourth section analyzes three CSR theories and sheds light on the core responsibility of every theory. Comprehensive analysis for the three recognized CSR models were represented in a table to help readers to locate and clarify systemic differences and common features between the three theories.

The last section of the article reveals three main outcomes, the first outcome represents a recommendation for the implementation process of adopting any of the three theories, and which is divided into an internal and external level. The second outcome reveals the importance of addressing a specialized committee for CSR by a company, followed by the third outcome that discusses some of the implications of this analysis for future CSR research and studies.
\end{abstract}

Keywords: corporate social responsibility, business corporations, community welfare..

DOI: $10.21303 / 2504-5571.2019 .001007$

\section{Introduction}

Over the last decades, CSR as a concept has attracted the attention of many researchers in the management sphere. In fact, most of them have created different models and theories concerning CSR concept, the matter that led to different approaches for CSR. From this point, it is sufficient to overview the commons and differences between various theories of CSR, in order to come up with a common implementing form for CSR approach that reflects the interest of shareholders and community as well.

CSR definitions, theories and models were investigated by many scholars. The main are Reza Safarzad, Milton Friedman, James Brusseau, Archie Carroll, R. Edward Freeman, Elisabet Garriga and Domenec Mele, Maryna Saprykina, Yaroslav Kutovy.

Reza Safarzad defined CSR concept as a legal requirement for a company which includes continued commitment toward the community. He added that the main goal of a company is to increase the efficiency and productivity of its operations and to maximize its shareholders' profit. But all this must be done by integrating the community ethical and environmental expectations into the company economic processes [1].

Milton Friedman was against the mentioned CSR concept as a whole, he believed that companies' management has only one responsibility which is to maximize the profits of its owners 
and shareholders. He argued that social problems should be resolved independently by free market system mechanism [2].

James Brusseau gave two definitions to CSR. First, it's a general name for any theory of the corporation that emphasizes both the responsibility to make money and the responsibility to interact ethically with the surrounding community. Second, CSR is a specific concept to achieve profit for a company while it plays a role in community welfare [3]. Then he added that CSR as a specific theory was composed of four companies' obligations:

- Economic responsibility to make money;

- Legal responsibility to adhere to rules and regulations;

- Ethical responsibility to do what's right even when not required by the letter or spirit of the law;

- Philanthropic responsibility to contribute to society's projects even when its independent of the particular business.

Archie Carroll was one of the most popular scholars at the management field who consolidated James Brusseau definitions for CSR, he created what is known nowadays as "Carroll's Pyramid of CSR". Carroll's four parts of CSR were originally stated as follows: CSR includes the economic, legal, ethical and philanthropic expectations that society has toward an organization. Later, at the basis of it he designed CSR pyramid. Through Carroll point of view, CSR obligations should be taken in order from bottom to top, from economic responsibility to legal to ethical to philanthropic. If a corporation achieve the first responsibility efficiently, then it can move to the next one [4].

R. Edward Freeman explored the relationship between two major concepts in business ethics: stakeholder theory and CSR. Freeman defined stakeholders as groups who had a stake in or claim on the firm. He meant that any group or person that had a contact or claim on the firm in business life or general life was a stakeholder. The stakeholders in his opinion are groups that have rights not to be treated as a means to some end and therefore must participate in determining the future direction of the firm in which they have a stake [5]. So according to Freeman CSR must follow goals of stakeholders.

Elisabet Garriga and Domenec Mele in their famous article "Corporate Social Responsibility Theories: Mapping the Territory" tried to classify the main CSR theories and related approaches in four groups:

1. The first group is the instrumental theories group, in which a corporation is seen as the only instrument for wealth creation, and company's social activity is to achieve its economic results.

2. The second group is the political theories group, where a corporation is responsible to use its power in political life. Supporting associations that aim to spread the culture of human rights, labor rights, women's rights and fight corruption in society lead to enhance the role political theories and provides transparency for true values of CSR.

3. The third group is the integrative theories group, in which a corporation is focused on satisfaction of social and ethical demands. Social development consists from supporting charities and welfare institutions such as orphanages, elderly centers, or funding youth and sports centers.

4. The fourth group is the ethical theories group, based on the ethical responsibilities of corporations to society. Ethical responsibility entails corporate commitment to respect the ethics of its society. For example, companies should consider transparency and credibility with its stakeholders [6].

Maryna Saprykina, director of the Corporate Social Responsibility Development Center in Ukraine mentioned that there is even legislation that requires companies to do CSR, for example in the European Union, large companies must publish their financial reporting in order to achieve transparency. Every year, English companies must publish a statement which clarifies that their suppliers give appropriate rights to their employee. In France, there is a law under which companies must carry out ecological audits in its operations [7]. 
Yaroslav Kutovy, The Head of Information Technology Department at the Ukraine Association Local Tech Industry mentioned that scholars interpret corporate social responsibility differently: for some it means creating comfortable conditions at work, for others giving equal conditions to all employees, and still for others providing recreational services, following recycling and environmental protection policies, and more [8]. All of these procedures are important for businesses to maintain a good image and thus win the competition to attract the best hires.

In practice, each of the CSR group's present different dimensions related to profits, political performance, environment demands, social demands, and ethical values. So in their opinion, the necessity is to develop a united framework for implementing CSR projects.

Multiplicity and dispersion of classifications for CSR theories scattered corporations from implementing useful CSR approaches. What we need is a real study that summarizes the common characteristics and features of CSR theories so a business corporation can target it through implementing CSR projects.

Dima Jamali and Charlotte Karam identify the key differentiating attributes of the literature on CSR in developing countries in relation to depictions of how CSR is conceived or 'CSR Thinking' and depictions of how CSR is practiced and implemented or 'CSR Doing' [9].

The aim of this article is to provide comprehensible and clear definition of CSR approach for business corporations, the approach that achieves benefits for both community and corporation.

\section{Materials and methods}

The article is divided into four main part. The first part explains Carroll CSR theory, the second explains the triple bottom line CSR theory and the third explains the stakeholder theory. The fourth part analyzes the similarities and differences between the three theories then summarizes it in one table.

\section{1. Carrol CSR Pyramid.}

Carroll made a specific theory for the way that corporation interact with its surrounding community and the whole world, this theory is known nowadays as Carroll's Pyramid of CSR (Fig. 1). Carroll's theory is composed of four obligations that create a foundation or infrastructure for the business's responsibilities toward society.

A. Economic responsibility. It's the obligation of a business organization to make money. Carroll placed the economic obligation in the base of the CSR Pyramid because it's vital for business survival. Any corporation or organization, even if it's a non-profitable organization, as charities association needs assets in order to succeed and sustain. According to Carroll, the first step in implementing CSR is to enroll in business operations and to make profits. Carroll added that profits are necessary to reward investors and owners. Moreover, profits must be reinvested back to maintain business growth. Economic responsibility is represented by a corporation through investments, marketing strategies, business operations, and long-term financial strategies with variant stakeholders. For example, when a corporation enrolls into business operations, it must hire a number of employees and it will deal with different stakeholders as vendors, sellers, marketing consultants, stockholders, investors, insurance companies, banks, and financial institutes. Variant stakeholders will be affected positively if corporation achieves profits, this what economic scholars named as Win-Win theory. As a result, stakeholders will make profits, money circulation process will improve and a corporation will successfully achieve its CSR economic responsibility.

B. Legal responsibility. Corporations must respect laws and regulations. According to Carroll's Pyramid theory, Legal Responsibility placed in the second level of the CSR Pyramid. A responsible corporation is a corporation that accepts rules of a fair business game. A responsible corporation adheres to law because it believes that fair business reflects positively on the whole economy and society. If a corporation makes tax evasion process, or deals with money laundering activities, or even produces a toxic product, it is illogical to consider it is sharing in CSR values.

C. Ethical responsibility. Corporations must behave as a good citizen in its society. Such responsibility allows corporations to make what is good for society even if the law didn't require it. Carroll mentioned that corporations must be responsive to the spirit of the law, not just to the letter 
of law. In other words, ethical responsibility embrace fair activities done by a corporation and expected by society. For example, fishing companies are allowed to hunt unlimited amounts of fish in the Middle East seabed, but it is immoral to hunt larger quantities than the quantity required by the market. Civil societies and associations play an important role in determining the ethical controls of companies until these controls become official laws.

D. Philanthropic responsibility. It is a voluntary activity guided by the business's desire to participate in social activities that are not mandated, not required by law, and not generally accepted in business as ethical sense. So philanthropic responsibility is a pure giving for society, it's an activity or project created by a corporation and purely dedicated to community expectation. At the philanthropic level, the business corporations could satisfy what is desired by their society. To fulfill in philanthropic responsibility, corporations engage in various giving forms, as sponsoring sports activities like an annual marathon or volunteering employees in donation campaigns, etc. The value behind philanthropic activities is to reveal a good citizenship image of the company and increase its reputation.

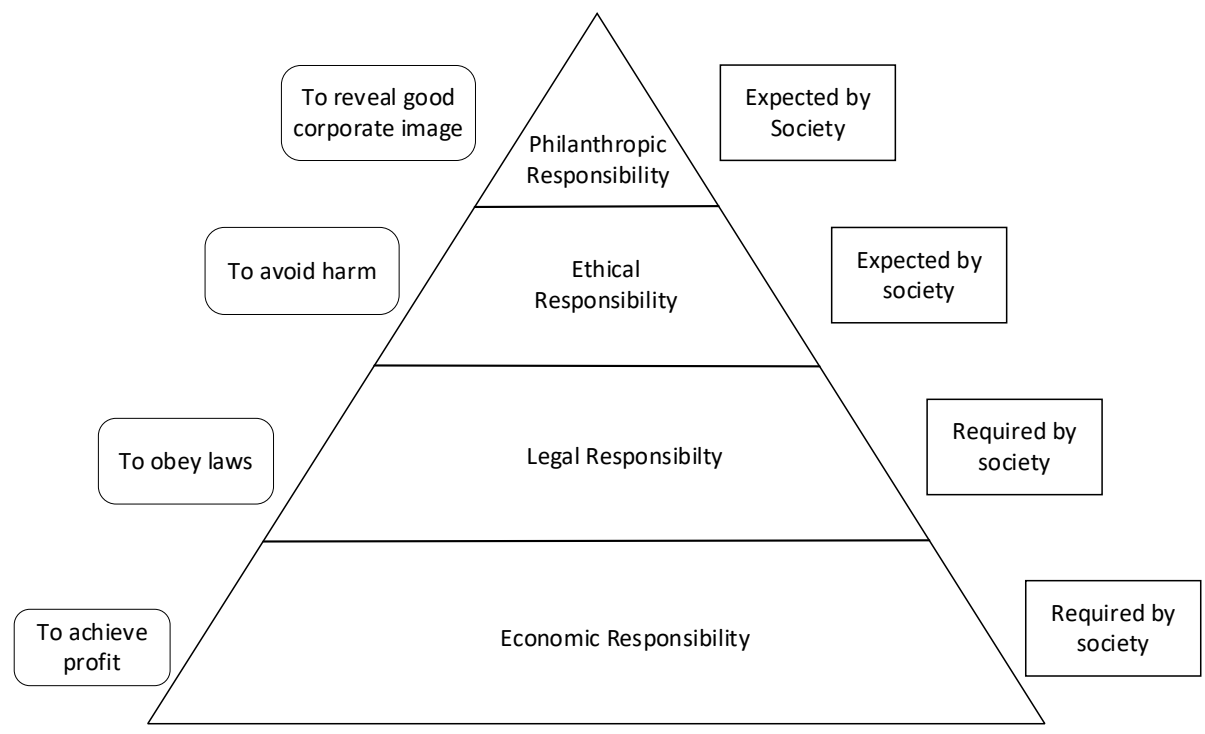

Fig. 1. Carroll Pyramid for CSR [4]

The main idea of Carroll Pyramid is to apply CSR projects in the order form. Companies should apply social responsibility by achieving economic objectives at the first level through maintaining sustainability and profitability. Only then it can move to the next stage which is the commitment to recognize regionally and internationally laws and obligations. Only after that third level come, which is the commitment to ethical standards. Finally achieving the last level, where companies contribute to the philanthropic responsibilities required by society and environment.

When Carroll developed his original four-part construct of CSR (1979) and then his pyramidal depiction of CSR (1991), it was clearly done with American-type capitalistic societies in mind. But in 2007 Crane and Matten observed that all the levels of CSR depicted in Carroll's pyramid play a role in Europe and interlink in some manner [12]. Likewise, Visser revisited Carroll's pyramid in developing countries/continents, particularly in Africa, and argued that the order of the CSR layers there differ from the classic pyramid. Visser mentioned that in developing countries, economic responsibility continues to get the most emphasis, but philanthropy is given the second highest priority followed by legal and then ethical responsibilities [13]. As a result, there are some other aspects must corporations shed the light on, as the nature and the situation of the surrounding environment and community before adopting Carroll CSR framework. In order to maximize the benefits of CSR, business needs to take into account the needs of the surrounding society and thus implement projects that are appropriate to it. 


\section{2. The Triple Bottom line Theory}

The Triple Bottom Line theory (TBL) was found by John Elkington in his book "Cannibals with Forks: The Triple Bottom Line of 21st Century Business" [14]. TBL can be considered as CSR framework that incorporates three dimensions of performance: economic, social and environmental. As elaborated by John Elkington, the three dimension of TBL must obtain sustainable results. Sustainability is the main aim of the TBL concept. Companies must apply TBL in order to achieve continuous profits and long-term social and environmental projects. Many corporations and nonprofit organizations have adopted the TBL sustainability framework to perform CSR projects.

Economic dimension. According to TBL theory the most important for a company is not to make high profits but to achieve continuous profit for the long term. So Business corporations start to enroll in the TBL CSR framework as well as they draw a strategic plan through calculating expenditures and taxes, forecasting business climate factors, evaluate market benchmark and avoid maximum risk threats. Real study for all these components will lead to achieve sustainable profits.

Social Dimension. Business must pay attention to its social affairs as well as paying attention to its financial affairs. Achieving social sustainability by a corporation is a must in the TBL CSR framework. But since societies differ from region to another, every corporation has to collect data from national authorities concerning social affairs, as unemployment rates, human rights, female labor force participation, health services, educational services provided by government, etc. After determining the community priorities, shareholders must take decisions to satisfy as much as possible the social needs. So for a business to be stable over the long term social activities of a business corporation must satisfy surrounding society needs as much as possible.

Environmental Dimension. Environmental sustainability is one of the main concepts in the TBL framework. If business companies will not respect the environmental dimension, our children will not be able to enjoy the same quality of life we are enjoying now. Corporations must pay attention to environmental changes and obey the new environmental laws with being careful to the consumption of natural resources. Corporations have to use the alternative energy sources in order to minimize the consumption of traditional sources of energy (for example oil, gas, coal, etc.), and it has to safe air and water sources, with disposing of toxic and solid waste in an environmental manner. All these factors maintain environmental sustainability.

It's clear that the flexibility of the TBL concept allows companies to implement social and environmental strategies in a sustainable manner. However Timothy F. Slaper (an economic research analyst) mentioned that there are challenges to put the TBL theory into practice [15]. These challenges include measuring each of the three categories, finding applicable data and calculating policy's contribution to sustainability [15]. Overcoming these challenges allows companies to take the correct long term decisions.

\section{3. The Stakeholder Theory}

Stakeholders are described broadly by Freeman and Reed as any identifiable group or individual who can affect the achievement of an organization's objectives or who are affected by the achievement of an organization's objectives [16]. Edward Freeman mentioned in his famous article "Strategic Management, A Stakeholder Approach" that a corporation has stakeholders, that is, groups and individuals who benefit connected with the corporation actions [16]. So stakeholders might be T. Thus, stakeholder theory proposes that objectives of a corporation can be only achieved by protecting and balancing the interests of different groups of stakeholders. As a descriptive theory stakeholder theory has been used to describe the nature of the firm, management of corporations, and how board directors think about the interests of corporate constituencies [17]. While from an instrumental perspective, the theory is used to identify the connection between stakeholder management and the CSR approach [18].

After defining stakeholder theory and its relationship with CSR, the main question is how to apply the stakeholder theory. Corporations, especially corporate directors and leaders can be more 
responsive to the interests of society as a whole by incorporating the participation of stakeholders in the corporation's boards of directors. In other words, every stakeholder of a corporation should be represented at least by one person in the board of directors of the corporation in order to share the interest of his group. After that, the board of director for a corporation will draw a strategy to align both corporation and stakeholders goals.

Realistically, according to The Stakeholder Theory and stakeholder ethics, if top managers are going to let every stakeholder actively participate in a corporation's decision making process, then those stakeholders need to be aware external and internal environment of the corporation. Directors in a corporation might hide important information regarding incomes or regarding some dangerous operations in the factory. Real example of this issue was the following, a civil action case was taken against W. R. Grace Factory (an American chemical factory, located Woburn city, Massachusetts State in the United States of America). W. R. Grace hid operations related to dumping its toxins wastes into the soil and in the river of Woburn city [19]. Dumping W. R. Grace toxic waste into Woburn River led to a very high rate of Leukemia cancer in Woburn city during the year 1996 and then led to the death of eight children in the city. Some of the politicians who are considered as stakeholders tried to protect W. R Grace factory since they received high amount of bribes, while other stakeholders as environmental organizations in the city and children's families demanded clean-up of contaminated areas and an apology. Later on, a decision was taken by the court of Woburn, owners of W. R. Grace must pay around 20 million dollars to clean up the land and the groundwater and to pay compensation to the families in the territory. In order to apply The Stakeholder Theory in clear way, companies must be transparent toward its operations with all stakeholders.

As a result, the risk in The Stakeholder Theory is that corporate directors would share the interest of stakeholders who are only interested in maximizing profits, across the spectrum of other stakeholders as people in the surrounding area, those whose lives are touched by the business operations.

\section{Result}

\section{1. Analyze the similarities and difference between the three theory concepts}

It seems obvious now that The Carroll Pyramid Theory and The Triple Bottom Line Theory have the same concern toward the economic obligation of CSR. In addition, The Stakeholder Theory gives high attention to the economic obligation, which is the interest of shareholders to maximize corporate profits. Consequently, there is conflict and dilemmas toward other responsibilities between the three theories.

In term of The Carroll CSR pyramid Theory, business corporations must concentrate on doing business legally, ethically and philanthropically. While the risk of such theory is that corporations might ignore many other external factors, especially social and environmental factors. Studying social and environmental needs for the surrounding community of a company must be done before applying Carrol CSR strategy, since these factors may change the priority and hierarchy of companies' responsibilities.

In term of The TBL theory, corporations must apply similar performance to Carroll Pyramid Theory regarding economic and social factors. But TBL theory added the environmental factors as one of the main factors of achieving business sustainability. The challenge for implementing TBL CSR theory into practice is to balance between the three responsibilities. It is no longer enough for a corporation to earn money only, it has a moral responsibility to achieve social and ecological objectives.

In terms of The Stakeholder Theory, the interest of all stakeholders must be well respected in corporate social responsibility strategies. It is important to keep in mind that the implementation of The Stakeholder Theory requires full transparency of all business processes with all stakeholders. The lack of transparency may allow business managers to exploit their influence and to ignore community's demands while achieving profits.

The main characteristics of the mentioned theories are presented in Table 1. 
Table 1

Summarizes main properties and characteristics for three CSR theories; The Carroll Pyramid theory,

The Triple bottom line theory and the stakeholder theory (created by authors)

\begin{tabular}{llll}
\hline \multirow{2}{*}{ CSR Theory } & \multicolumn{1}{c}{ Strength of the Theory } & \multicolumn{1}{c}{$\begin{array}{c}\text { Characteristics of CSR Theories } \\
\text { Applying the Theory }\end{array}$} & \multicolumn{1}{c}{$\begin{array}{c}\text { Challenges in } \\
\text { Applying the Theory }\end{array}$} \\
\cline { 2 - 4 } $\begin{array}{l}\text { The Carroll CSR } \\
\text { Theory }\end{array}$ & $\begin{array}{l}\text { - Taking into account four } \\
\text { main responsibilities for CSR } \\
\text { approach: economic, legal, } \\
\text { ethical and philanthropic } \\
\text { - Arranging the four } \\
\text { responsibilities in the order of the } \\
\text { hierarchy }\end{array}$ & $\begin{array}{l}\text { - Revealing good citizen image } \\
\text { for corporation } \\
\text { - Improving the reputation of } \\
\text { corporations }\end{array}$ & $\begin{array}{l}\text { Before implementing the Carroll } \\
\text { CSR theory, external social and } \\
\text { environmental situations must } \\
\text { be studied; it will take more time } \\
\text { and effort to apply the theory }\end{array}$ \\
$\begin{array}{l}\text { The Triple Bottom } \\
\text { Line Theory }\end{array}$ & $\begin{array}{l}\text { Taking into account three main } \\
\text { responsibilities for CSR ap- } \\
\text { proach: economic, social and } \\
\text { environmental }\end{array}$ & $\begin{array}{l}\text { Supporting the corporation to } \\
\text { achieve sustainability }\end{array}$ & $\begin{array}{l}\text { When using the approach any } \\
\text { corporation has to balance } \\
\text { between the three CSR respon- } \\
\text { sibilities in order to achieve } \\
\text { sustainable goals in society and } \\
\text { ecology }\end{array}$ \\
$\begin{array}{l}\text { The Stakeholder } \\
\text { Theory }\end{array}$ & $\begin{array}{l}\text { Taking into account the interest } \\
\text { of various stakeholders groups }\end{array}$ & $\begin{array}{l}\text { Allowing the corporation to } \\
\text { maintain a strong interrelation } \\
\text { and interconnection with com- } \\
\text { munity and business compo- } \\
\text { nents. If the aim is achieved, the } \\
\text { company will gain the trust and } \\
\text { loyalty of all stakeholders }\end{array}$ & $\begin{array}{l}\text { When using the approach any } \\
\text { corporation has to balance the } \\
\text { interests of all stakeholders and } \\
\text { adopt a transparent policy with } \\
\text { them }\end{array}$ \\
\end{tabular}

\section{2. Outcomes}

Through this study it has been realized that there are some common features and charactarestics for the three CSR theories. So corporations could target these common features during the implementation process of any CSR theory. The implementation process of any CSR theory could be divided into two levels, endogenous level (inside the firm) and exogenous level (outside the firm).

Internally, the CSR implementation process must:

- Respect all human rights within the establishment and fulfill the demands of employees.

- Comply with the conditions and laws of the ecology and apply them in the production line and rely on renewable energy sources such as solar panels.

- Ensure quality standards within the facility.

Externally, the CSR implementation process must:

- Maintaine transparency with all stakeholders through publicating Income statements and Project Milestones on media and internet networks.

- Sponser social activities outside the establishment which directly affect the community welfare such as: schools, sport institutions, hospitals and nursery homes.

- Ensure that products and services delivered to consumers does not pollute the enviroment.

Its recommanded also for every company to form a specialized committee for CSR implementation process (Fig. 2). The role of this committee is to choose the appropriate corporate social responsibility theory and prepare an initial plan for implementing it. Moreover the committee must review achievements and feedbacks of its CSR implementation process.

The diagram represents the role of a specialized committee in a corporation to choose the appropriate CSR theory and implement it on the internal and external level. There is no doubt that CSR theories have similar objectives which is innovating approaches that contribute to the economic stability, environmental sustainability and social development with all stakeholders [20]. But there is a need in the future to determine how a company can make decision toward choosing the appropriate CSR theory. 

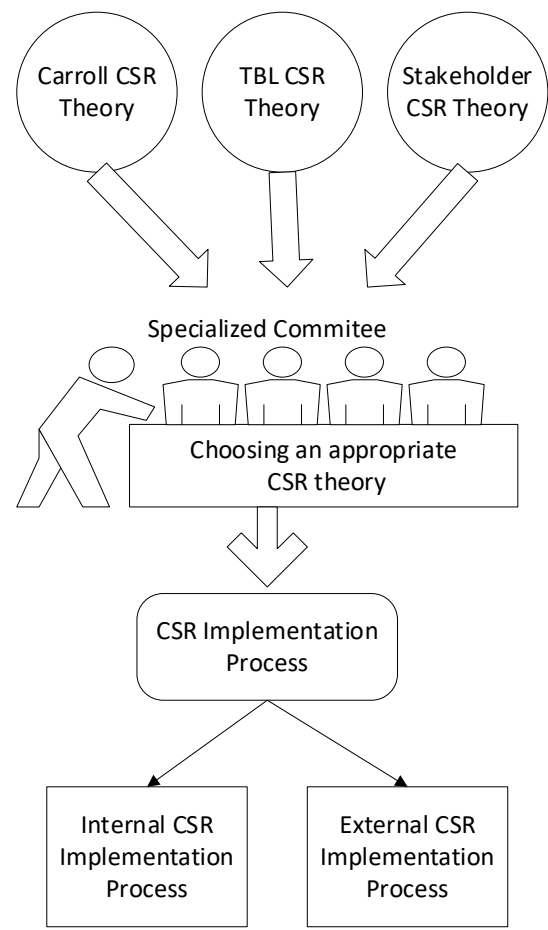

Fig. 2. Decision making about implementing of CSR (created by authors)

\section{Conclusions}

In the article three of the main CSR theories have been represented and analyzed: The Carroll Theory, The Triple Bottom Line Theory, and The Stakeholder Theories. At the bases of the conducted analysis it has been defined common features and charactarestics for the mentioned CSR theories.

The process of implementating of any any CSR approach shoud be divided into two levels: endogenous and exogenous.

It is proposed to form a specialized committee for CSR implementating in any company. The main objective of this committee is to select the most appropriate CSR theory and craft a strategy for its implementing.

\section{References}

[1] Safarzad, R. (2017). Corporate Social Responsibility Theories and Models, Applied mathematics in engineering. Management and technology journal, 5, 38 .

[2] Friedman, M. (1962). The Capitalism and Freedom. University of Chicago Press.

[3] Brussaeau, J. (2011). The Business Ethics Workshops. Boston Academic Publishing. Vol. 1.

[4] Carroll, A. B. (2016). Carroll's pyramid of CSR: taking another look. International Journal of Corporate Social Responsibility, 1 (1). doi: https://doi.org/10.1186/s40991-016-0004-6

[5] Freeman, R. E., Dmytriyev, S. (2017). Corporate Social Responsibility and Stakeholder Theory: Learning from each other. SYMPHONYA Emerging Issues in Management, 1. doi: http://dx.doi.org/10.4468/2017.1.02freeman.dmytriyev

[6] Garriga, E., Melé, D. (2004). Corporate Social Responsibility Theories: Mapping the Territory. Journal of Business Ethics, 53 (1/2), 51-71. doi: https://doi.org/10.1023/b:busi.0000039399.90587.34

[7] Maryna Saprykina promotes corporate social responsibility in Ukraine (2018). Available at: https://www.kyivpost.com/business/maryna-saprykina-promotes-corporate-social-responsibility-in-ukraine.html

[8] Ukraine's IT firms embrace CSR as key path to success (2018). Available at: https://www.kyivpost.com/technology/ukrainesit-firms-embrace-csr-as-key-path-to-success.html

[9] Jamali, D., Karam, C. (2016). Corporate Social Responsibility in Developing Countries as an Emerging Field of Study. International Journal of Management Reviews, 20 (1), 32-61. doi: https://doi.org/10.1111/ijmr.12112

[10] Soylu, S., Azizzadeh, S. (2018). Is Corporate Social Responsibility Always A Function Of Good Management? Academy of Management Proceedings, 2018 (1), 11219. doi: https://doi.org/10.5465/ambpp.2018.11219abstract 
[11] Bhardwaj, P., Chatterjee, P., Demir, K. D., Turut, O. (2018). When and how is corporate social responsibility profitable? Journal of Business Research, 84, 206-219. doi: https://doi.org/10.1016/j.jbusres.2017.11.026

[12] Crane, A., Matten, D. (2016). Business ethics: managing corporate citizenship and sustainability in the age of globalization. Oxford University Press, 87.

[13] Wayne, V. (2010). The age of responsibility: CSR 2.0 and the new DNA of business. Emerald Group Publishing Limited, 231.

[14] Elkington, J. (1998). Partnerships from cannibals with forks: The triple bottom line of 21st-century business. Environmental Quality Management, 8 (1), 37-51. doi: https://doi.org/10.1002/tqem.3310080106

[15] Slaper, T. F., Hall, T. J. (2011). The Triple Bottom Line: What Is It and How Does It Work? Indiana Business Review, 86 (1). Available at: http://www.ibrc.indiana.edu/ibr/2011/spring/article2.html\#ftn2

[16] Freeman, E. (2010). Strategic Management: A Stakeholder Approach. Cambridge University Press. doi: https://doi.org/10.1017/ cbo9781139192675

[17] Brenner, S. N., Cochran, P. (1991). The Stakeholder Theory of the Firm. Proceedings of the International Association for Business and Society, 2, 897-933. doi: https://doi.org/10.5840/iabsproc1991235

[18] Kotter, J. P., Heskett, J. L. (1992). Corporate Culture and Performance. Free Press, 45. Available at: https://books.google.com.ua/ books?id=pWudzigl0ucC\&printsec $=$ frontcover\&dq $=$ Corporate + Culture + and + Performance + Kotter, + J.P. + and + Heskett\&hl $=-$ fr\&sa $=$ X\&ved=0ahUKEwjbht271_nfAhWF3iwKHal3B1oQ6AEIKzAA\#v $=$ onepage\&q=Corporate $\% 20$ Culture $\% 20$ and $\% 20$ Performance\%20Kotter\%2C\%20J.P.\%20and\%20Heskett\&f=false

[19] Case Summary. Available at: https://serc.carleton.edu/woburn/Case_summary.html

[20] Brin, P., Nehme, M. (2018). Corporate Social Responsibility: Possible Approaches for Unemployment Production. Business Navigator Scientific Journal, 2-2 (45). 